Revista Brasileira de Agricultura Irrigada v.8, no. 1, p. 52 - 63, 2014

ISSN 1982-7679 (On-line)

Fortaleza, CE, INOVAGRI - http://www.inovagri.org.br

DOI: $10.7127 /$ rbai.v8n100198

Protocolo 198.13 - 21/11/2013 Aprovado em 20/02/2014

\title{
MANEJO DA IRRIGAÇÃO NO FEIJOEIRO, CULTIVADO EM SEMEADURA DIRETA E CONVENCIONAL
}

José Joaquim Carvalho ${ }^{1}$, João Carlos Cury Saad ${ }^{2}$, Fernando Nobre Cunha ${ }^{3}$, Nelmício Furtado da Silva ${ }^{4}$, Marconi Batista Teixeira ${ }^{5}$

\section{RESUMO}

O Brasil é o maior produtor e consumidor de feijão comum Phaseolus vulgaris L cultivado por décadas principalmente pela agricultura familiar e, atualmente cultivado por produtores rurais com elevado níveis tecnológicos, no incremento da produtividade. O déficit hídrico e ou excesso de água no solo, ocasiona efeito direto no rendimento de grãos; nesse sentido observa-se que o crescimento das plantas é um dos processos fisiológicos mais sensíveis ao déficit hídrico, assim a irrigação exerce influência positiva na produtividade vegetal, desde que associado ao adequado manejo da mesma. O Estado de São Paulo, de maneira geral, apresenta períodos secos e chuvosos bem definidos. O presente trabalho teve por objetivo avaliar três métodos de manejo de irrigação: por tensiometria, tanque classe A, e pela evapotranspiração estimada pela equação de Penman-Monteith, todos aplicados em dois manejos de solo: plantio direto e convencional. A semeadura da cultivar BRS Pontal foi realizada em 29/09/2008, em sucessão ao cultivo de aveia preta numa área que estava em repouso há três anos. Avaliaram-se a produtividade de grãos, número de vagens por planta, número de grãos por vagem, massa de 1000 grãos, Número de vagens chochas, lâmina total e eficiência de uso da água. Os resultados do manejo da irrigação baseado no tanque Classe A e o de Penman-Monteith apresentaram uma lâmina média aplicada maior que o do tensiômetro.

Palavras-chave: produtividade, irrigação, comparação de métodos, Phaseolus vulgaris L, manejo do solo.

\section{MANAGEMENT OF IRRIGATION IN BEAN GROWN IN DIRECT SEEDING AND CONVENTIONAL}

\footnotetext{
ABSTRACT

Brazil is the largest producer and consumer of common bean Phaseolus vulgaris $\mathrm{L}$ is currently the most cultivated in the world. Before mainly grown by family farmers, but the

${ }^{1}$ Pós-Doutorando em Ciências Agrárias, Instituto Federal Goiano - Câmpus Rio Verde, Rodovia Sul Goiana, Km 01, CEP: 75.901-170, Rio Verde - GO, e-mail: josejoaquimcarvalho@yahoo.com.br

${ }^{2}$ Eng $^{0}$ Agrônomo, Prof. Dr. Adjunto, (FCA/UNESP), Departamento de Engenharia Rural.

${ }^{3}$ Mestranda em Ciências Agrárias, IFG - Câmpus Rio Verde, e-mail: fernandonobrecunha@hotmail.com

${ }^{4}$ Mestranda em Ciências Agrárias, IFG - Câmpus Rio Verde, e-mail: nelmiciofurtado@gmail.com

${ }^{5}$ Eng. Agrônomo, Prof. Dr. em Agronomia, IFG - Câmpus Rio Verde, e-mail: marconibt@gmail.com
} 
bean has been cultivated by farmers who have the most varied levels of technology, increase in productivity. The drought and excess water or soil, causes a direct effect on grain yield and in this sense it is observed that plant growth is a physiological process most sensitive to water deficit, so irrigation has a positive influence on plant productivity from that associated with the proper management of the same. In general, Sao Paulo state presents defined periods of dry and rainy seasons. During rainy season, rainfall distribution is irregular, decreasing the bean yield when the dry period coincides with the crop critical water stage. The objective of the study was to evaluate three irrigation scheduling methods: tensiometer, Class A Pan evaporation, and evapotranspiration estimated by Penman-Monteith equation, all of them combined with two soil management conditions: conventional and no-tillage. The bean sowing was accomplished on 09/29/2008 using cultivate BRS Pontal. Previously this experiment, black oats culture was cultivated in an area which was fallow for three years. The results showed that there was differences among irrigation scheduling methods in the conventional soil management and all treatments in this study showed significantly higher yields than the non-irrigated treatment. In the conventional soil management all irrigation scheduling methods provided larger applied water efficiency compared to no-tillage.

Keywords: productivity, irrigation, comparison of methods, Phaseolus vulgaris, soil management

\section{INTRODUÇÃO}

O Brasil é o maior produtor e consumidor mundial de feijão (Phaseolus vulgaris L.), e os principais estados produtores são Paraná, Bahia, Minas Gerais, Mato Grosso, São Paulo, Goiás, os quais respondem por mais de $67 \%$ da produção nacional. Produzindo aproximadamente três milhões de toneladas, com uma produtividade média de $910 \mathrm{~kg} \cdot \mathrm{ha}^{-1}$ referente a safra 2012/2013, (CONAB, 2014). Esta baixa produtividade média nacional está relacionada ao pouco uso das tecnologias disponíveis empregado, principalmente pela agricultura familiar (GALBIATTI et al., 2011). Porém, produtividades acima de $3.000 \mathrm{~kg} \cdot \mathrm{ha}^{-1}$ podem ser alcançadas em lavouras irrigadas e com alto nível tecnológico.

A cultura do feijão possui ampla adaptação edafoclimática, podendo ser cultivada durante todo o ano, em quase todos os estados brasileiros, pois não apresenta sensibilidade ao fotoperíodo, desde que não ocorram limitações de temperatura e umidade (ABRANTES et al., 2011). Temperaturas maiores do que $35^{\circ} \mathrm{C}$ no florescimento, afeta bastante o rendimento de grãos. Da mesma forma, temperaturas abaixo de $12^{\circ} \mathrm{C}$ podem provocar abortamento de flores, concorrendo para um decréscimo no rendimento. A maior parte da produção é procedente de microrregiões com temperaturas do ar variando de $17^{\circ} \mathrm{C}$ a $25^{\circ} \mathrm{C}$, faixa térmica considerada apropriada para a espécie (GONZAGA; BARBOSA, 2012).

A exigência hídrica da cultura do feijão depende das condições climáticas locais, sendo de modo geral encontra-se numa faixa de 300 a 600 mm de água, distribuídos durante o ciclo da cultura (SILVEIRA; STONE, 2004; PAVANI et al., 2008). 
Nas regiões com distribuição de chuvas irregulares podem ocorrer perdas significativas no rendimento, especialmente quando a falta de água coincide com os períodos críticos de desenvolvimento da cultura de feijão. Cunha e Martins (2009) relatam que no município de Botucatu, SP, o valor médio de precipitação pluvial anual, calculado para uma serie histórica de 36 anos (1971 a 2006), é de 1.428,4 mm, sendo que o período chuvoso está concentrado nos meses de janeiro, fevereiro, março, setembro, outubro e novembro, com índices hídricos relativamente elevados.

O feijoeiro é sensível tanto à deficiência hídrica quanto ao excesso de água no solo (SILVEIRA; STONE, 2004). A duração, a intensidade, a frequência e a época de ocorrência do estresse interferem na maioria dos processos fisiológicos e morfológicos das plantas, interferindo prejudicialmente nos componentes do rendimento (NÓBREGA et al., 2004). A técnica de irrigação tem como objetivo o fornecimento de água às culturas, de modo a suprir as exigências hídricas nas diferentes fases de desenvolvimento. Tais exigências irão depender fundamentalmente das condições climáticas vigentes e da disponibilidade de água no solo. A deficiência hídrica nas plantas é tanto maior quanto menor o suprimento de água às raízes (GUIMARAES et al., 2006), e os efeitos causados dependem da duração, do tipo de estresse e da severidade durante o ciclo da planta. Este reduz o tamanho das folhas e ramos (TAIZ; ZIEGER, 2009), com efeito indireto no rendimento de grãos.

O manejo da irrigação do feijoeiro se constitui de um conjunto de procedimentos que visa atender as necessidades hídricas da cultura, propiciando o desenvolvimento e a máxima pro- dutividade (SILVEIRA et al., 2009), tornando cada vez mais necessária sua utilização, elevando a uniformidade de distribuição e a eficiência de uso da água (ALVES JUNIOR, 2010).

Quanto ao manejo das irrigações, Silveira et al. (2009) cita três deles, os quais são baseados nos fatores climáticos, na disponibilidade de água do solo e nas plantas. Podem ser feitas a conjugação do controle da irrigação via atmosfera e solo, o que é desejável, uma vez que os métodos de controle são por estimativas.

Dentre os métodos de estimativa da ETo, os mais precisos são aqueles fundamentados nos processos físicos da evaporação da água e da evapotranspiração da cultura de referência (grama), como é o caso dos métodos do tanque classe A (TCA) e de Penman-Monteith,(PM) respectivamente (SILVA; BARRETO, 2004). O método de PM é considerado padrão pela FAO para cálculo de ETo (ALLEN et al., 1998), e quanto à sua utilização são empregados dados de temperatura (T), umidade relativa (UR), radiação solar (Rs) e velocidade do vento (V). Para o método do (TCA), no qual a ETo é calculada multiplicando-se os valores diários da evaporação do tanque por um coeficiente Kp, função da distância da bordadura ao redor do tanque, da velocidade do vento e da umidade relativa do ar. De uso bastante generalizado, inclusive no Brasil, em virtude de seu custo relativamente baixo e fácil manejo (BRAGA et al., 2008).

Segundo Silveira e Stone (2004), o tensiômetro deve ser instalado na linha do feijoeiro em duas profundidades, a $15 \mathrm{~cm}$ e a 30 $\mathrm{cm}$, um ao lado do outro. Para este conjunto dáse o nome de bateria, sendo que a leitura do tensiômetro a $15 \mathrm{~cm}$ indica a tensão média da 
camada superficial do solo, a qual engloba a quase totalidade das raízes do feijoeiro, sendo chamado de tensiômetro de decisão e indica o momento de irrigar (SILVEIRA; STONE, 2004). O tensiômetro instalado a $30 \mathrm{~cm}$ foi denominado de controle, por indicar em caso de falta ou excesso de água no solo.

Cunha et al., (2013), verificaram que a lâmina total estimada por tensiometria foi 29,7 e $17,8 \%$ menor que a estimada pelos métodos do tanque e de Penman-Monteith, respectivamente, em semeadura direta. Pavani et al., (2008), verificaram que a lâmina total estimada por tensiometria foi 17,2 e 26,2\% menor que a estimada pelo método do tanque classe $\mathrm{A}$, em semeadura direta e convencional, respectivamente.

Este trabalho teve como objetivo avaliar três métodos de manejo de irrigação assim descrito: manejo de irrigação por tensiometria (TS), evapotranspiração com base no tanque classe A e evapotranspiração com base na equação de Penman-Monteith, nos sistemas de plantio direto e convencional na cultura do feijoeiro.

\section{MATERIAL E MÉTODOS}

O experimento foi conduzido na área experimental do Departamento de Engenharia Rural da Faculdade de Ciências Agronômicas, em Botucatu - SP (latitude 22\%51'S, longitude 4826'W e 786 m de altitude). Segundo Cunha e Martins (2009), o clima da região é definido, conforme a classificação de Köppen, como Cfa (clima temperado quente úmido, mesotérmico, sendo a temperatura média do mês mais quente superior a $22^{\circ} \mathrm{C}$ ), e de acordo com a classificação de Thorntwaite é caracterizado como $\mathbf{B}_{2} \mathbf{r B}{ }_{3} \mathbf{a}^{\prime}$ (clima úmido com pequena deficiência hídrica em abril, julho e agosto), mesotérmico com evapotranspiração potencial anual de 945,15mm e concentração da evapotranspiração potencial no verão igual a 33\%. O solo da área experimental é classificado como Nitossolo Vermelho Distroférrico, textura argilosa (EMPRAPA, 2006).

O delineamento experimental utilizado foi o de blocos casualizados em esquema fatorial 4 x 2 com quatro repetições, com o primeiro fator representando uma testemunha sem irrigação (TO) e mais três métodos de manejo de irrigação e o segundo fator representando dois sistemas de plantios, sendo o PC e o PD.

Os tratamentos, além de TO, foram três métodos de manejo de irrigação e dois sistemas de plantio assim descritos: manejo da irrigação por tensiometria (TS), pelo balanço hídrico baseado no (TCA), e baseado na equação de (PM); sistemas (PC), em que se realizaram uma aração e duas gradagens, e (PD), em que foi aplicado o herbicida dessecante antes da semeadura.

O plantio da cultivar Pontal BRS foi realizado em 29/09/2008 numa área de 57,0 m x 19,2 $\mathrm{m}$, sendo as parcelas experimentais de $5 \mathrm{~m}$ x 1,8m com quatro linhas de feijão e três linhas laterais de gotejadores nas entrelinhas. $\mathrm{O}$ espaçamento entre fileiras de feijoeiro foi de 0,45 m, com 14 sementes por metro. A pressão 
de serviço na entrada da linha lateral era de 98,06 kPa e os emissores possuíam espaçamento de $0,2 \mathrm{~m}$ e vazão de $1,18 \mathrm{~L} \mathrm{~h}^{-1}$ por gotejador.

Foram utilizadas seis baterias de tensiômetros com manômetro de mercúrio, sendo três em cada sistema de plantio. Cada bateria apresentava dois tensiômetros instalados nas profundidades de $0,15 \mathrm{~m}$, utilizado para a tomada de decisão de quando irrigar (PAULA JUNIOR et al., 2008) e a 0,30 m, considerado de controle (SILVEIRA; STONE, 2004), todos instalados na linha do feijoeiro.

A adubação utilizada, com base em análise de solo e recomendação de Raij et al. (2001), foi de $214 \mathrm{~kg} \cdot \mathrm{ha}^{-1}$ da fórmula de $\mathrm{N}$, $\mathrm{P}_{2} \mathrm{O}_{5}, \mathrm{~K}_{2} \mathrm{O}+\mathrm{Zn}$ (8-28-16-0,5) aplicada no sulco da semeadora e $70 \mathrm{~kg} \cdot \mathrm{ha}^{-1}$ de $\mathrm{N}$, na forma de ureia, aos 25 dias após emergência, e 1 kg.ha 1 de micronutriente Boro na forma de ácido bórico a 17\%, parcelado em três aplicações (06/11/2008, 10/11/2008 e 14/11/2008). No (PD) a semeadura foi feita sob os resíduo de cultura de aveia preta após aplicação de herbicida glifosato, contendo 3,3 t.ha ${ }^{-1}$ de palha na superfície do solo, e no (PC) realizada após uma aração e duas gradagens com enxada rotativa.

As sementes foram tratadas com fungicida para o controle da podridão radicular (Furasin) (Rizoctonia solani) e da antracnose (Colletotrichum lindemuthianum), e com inseticida (Tiametoxam), para o controle da mosca branca (Bemisia tabaci) e da vaquinhaverde-amarela (Diabrotica speciosa). Também foi aplicado herbicida seletivo para a cultura do feijoeiro.

Em cada manejo de solo, a irrigação foi realizada quando a média das leituras diárias dos três tensiômetros instalados a $15 \mathrm{~cm}$ de profundidade atingiu o valor da tensão de irrigação, que era de $30 \mathrm{kPa}$ (PAULA JUNIOR et al., 2008; STONE et al., 2006). Para calcular a lâmina de irrigação, considerou-se o intervalo de umidade compreendido entre a tensão de irrigação $30 \mathrm{kPa}$ e a capacidade de campo, correspondente ao valor de $10 \mathrm{kPa}$.

Os valores da umidade do solo, em base volumétrica, correspondentes ao momento de irrigar e à capacidade de campo foram, respectivamente, de $31,25 \%$ e $34,47 \%$ para o sistema PD, e respectivamente, de $25,47 \%$ e $28,24 \%$ para o sistema PC. Considerou-se a eficiência do sistema de irrigação como sendo de $90 \%$ e a lâmina de água total necessária em cada irrigação era de $11 \mathrm{~mm}$ para o sistema PD e de $10 \mathrm{~mm}$ para o sistema PC. Considerando uma profundidade efetiva de $0,3 \mathrm{~m}$.

O balanço hídrico foi realizado de forma simplificada, levando-se em consideração a curva característica do solo, a precipitação pluviométrica, a irrigação e a evapotranspiração de referência.

Os coeficientes de cultura utilizados para determinar a evapotranspiração da cultura foram os descritos por Doorenbos e Kassam (1994) conforme os estádios fenológicos: estabelecimento 0,35, desenvolvimento vegetativo 0,75, florescimento 1,1 , frutificação 0,70 e maturação 0,3. O coeficiente do (TCA) foi determinado 
segundo metodologia descrita em Snyder (1992).

A colheita, realizada entre os dias 22/12 e 29/12/2009, concentrou-se na área útil da parcela, considerada como sendo $3 \mathrm{~m}$ de comprimento das duas fileiras centrais de plantas. Foram avaliados os seguintes componentes de produção: produtividade de grãos kg.ha ${ }^{-1}$; massa de 1.000 grãos; número de vagens por planta, número de grãos vagens, número vagens chochas.ha $^{-1}$. A debulha foi feita manualmente. Determinou-se a umidade dos grãos e a produtividade foi corrigida para a umidade de $13 \%$. A eficiência no uso da água pela cultura foi calculada por meio da razão entre a produtividade média de grãos e o volume total de água recebido durante os o ciclo da cultura.

De posse dos dados realizou-se a análise de variância para cada variável. Para as variáveis que mostraram efeito significativo dos tratamentos pelo teste $\mathrm{F}$, procedeu-se à comparação de médias pelo teste de Tukey a 0,05 de probabilidade.

\section{RESULTADOS E DISCUSSÃO}

A temperatura média do ar foi de 21, $37^{\circ} \mathrm{C}$, sendo a mínima de $16,90{ }^{\circ} \mathrm{C}$ e a máxima de $27,31{ }^{\circ} \mathrm{C}$. De maneira geral, os valores se encontram-se dentro da faixa térmica considerada apropriada para a espécie (GONZAGA; BARBOSA, 2012).

A ocorrência da precipitação pluviométrica acumulada no período estudado foi de
248,9 mm. A evapotranspiração estimada do feijoeiro (ETc) ao longo do ciclo, utilizando os métodos de manejo da irrigação pelo TCA e $\mathrm{PM}$, foi de $307,40 \mathrm{~mm}$ e $297,43 \mathrm{~mm}$, respectivamente, não diferindo para os sistemas de PD e PC (Figuras 2, 3, 4 e 5). Os valores médios diários da ETc obtidos para os métodos de manejo da irrigação TCA e PM foram, respectivamente, de $3,57 \mathrm{~mm}$ e de $3,46 \mathrm{~mm}$, para os sistemas PD e PC.

Devido à ocorrência dos veranicos no período estudado, principalmente na fase de maior exigência hídrica da planta, que é a fase reprodutiva, a irrigação foi necessária e complementar ao fornecimento hídrico, assegurando a produção (Figuras 1 a 6).

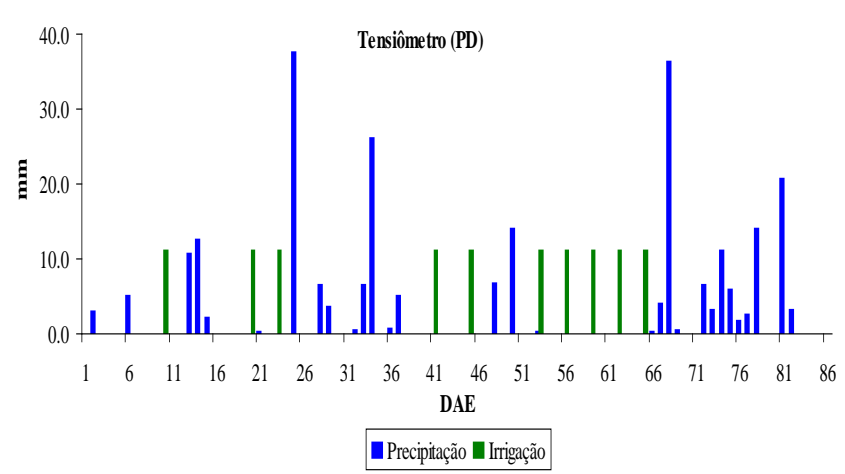

Figura 1. Precipitação pluviométrica e irrigação utilizando o método TS no sistema PD.

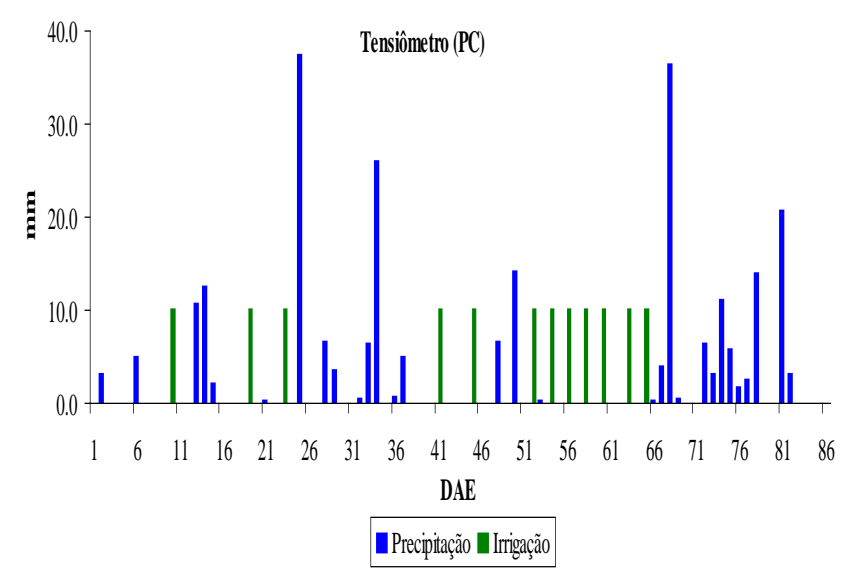

Figura 2. Precipitação pluviométrica e irrigação utilizando o método TS no sistema PC. 


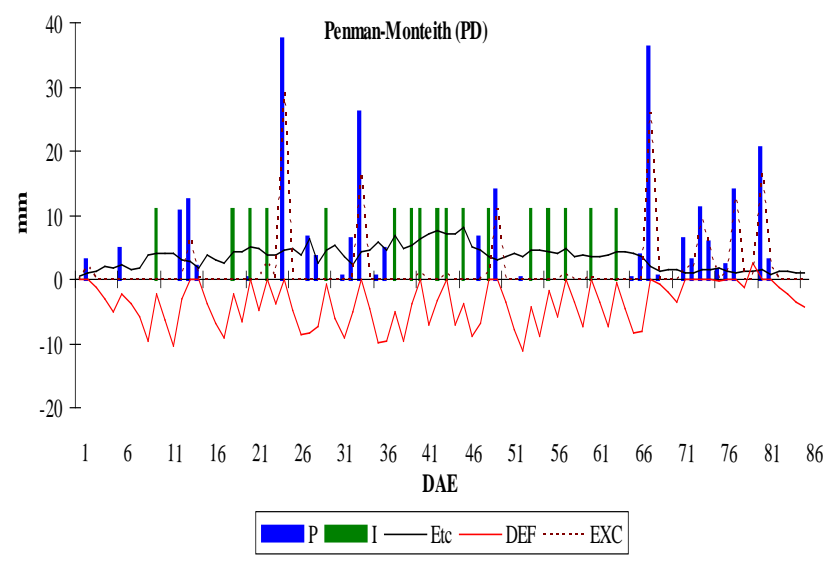

Figura 3. Precipitação pluviométrica (P), irrigação (I) e evapotranspiração da cultura (ETc), utilizando o manejo PM no sistema PD.

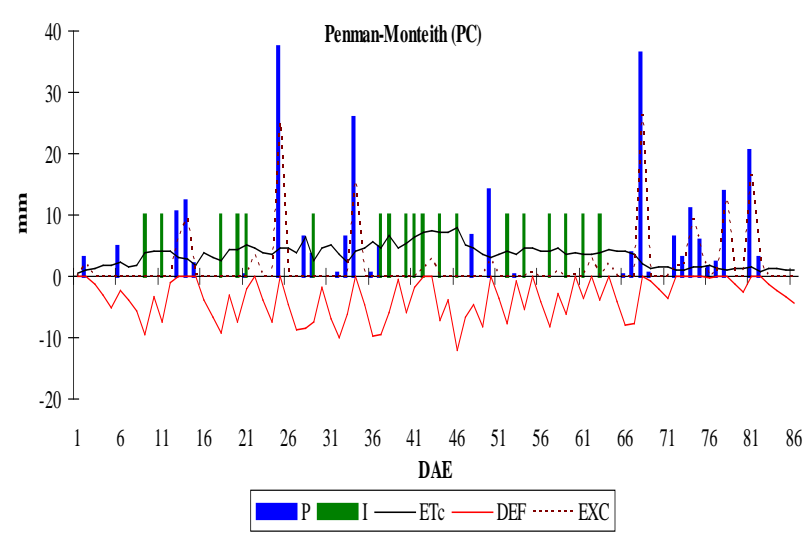

Figura 4. Precipitação pluviométrica (P), irrigação (I) e evapotranspiração da cultura (ETc), utilizando o manejo PM no sistema PC.

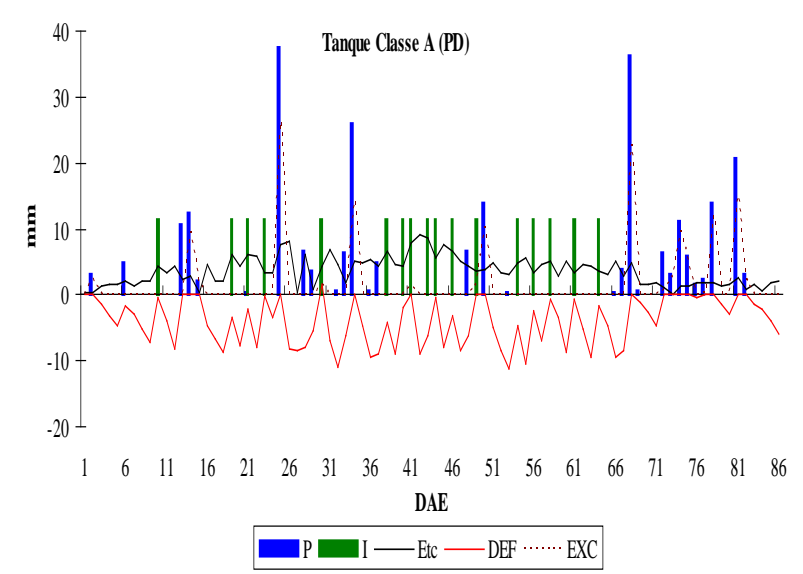

Figura 5. Precipitação pluviométrica $(\mathrm{P})$, irrigação (I) e evapotranspiração da cultura (ETc), o manejo TCA no sistema PD.

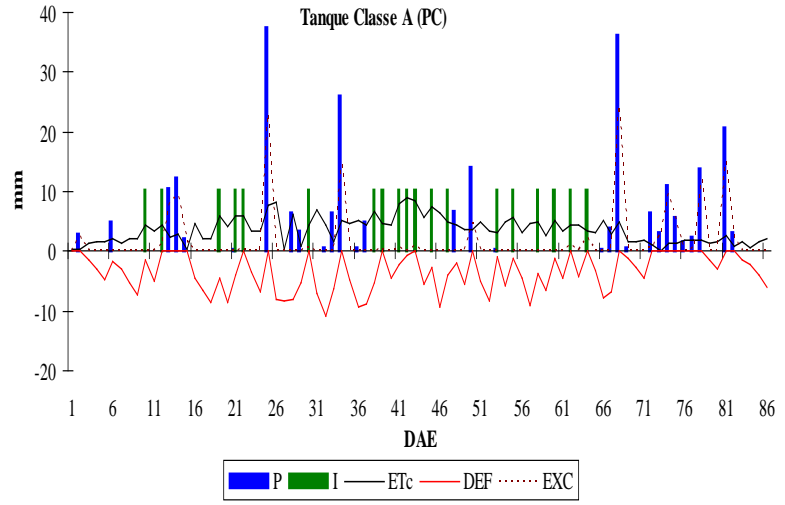

Figura 6. Precipitação pluviométrica (P), irrigação (I) e evapotranspiração da cultura (ETc), utilizando o manejo TCA no sistema PC.

Utilizando-se o método do TS nos sistemas PD e PC, a irrigação foi de $110 \mathrm{~mm}$ e $120 \mathrm{~mm}$ respectivamente, (Tabela 1 ) durante o ciclo de cultivo. Já com o método PM estes foram de $187 \mathrm{~mm}$ e $190 \mathrm{~mm}$ nos sistemas PD e PC, respectivamente e de 192,6 mm e 195,7 mm para o método TCA nos sistemas PD e PC, respectivamente (Tabela 1 ).

As irrigações foram feitas até os $64 \mathrm{DAE}$ e após este não houve necessidade em decorrência das precipitações pluviométricas ocorridas e também porque as plantas já se encontravam em fase final de ciclo.

Quanto aos métodos de manejo de irrigação avaliados, TCA, PM e TS, o que apresentou menor lâmina aplicada foi utilizando o TS, em ambos os sistemas de plantio. Por outro lado, a maior lâmina aplicada foi com o manejo via TCA, pois este superestimou em $18,6 \%$ e $17 \%$, respectivamente, nos sistemas de PD e PC, em relação ao manejo pelo TS. No sistema PC o manejo da irrigação pelo TCA resultou na maior produtividade de grãos. Já no $\mathrm{PD}$, não ouve diferença significativa entre os 
métodos avaliados quanto à produtividade de grãos. Pavani et al., (2008) observou que o PD é menos susceptível às variações hídricas no solo em relação ao plantio convencional.

No sistema PD, a precipitação pluviométrica mais irrigação utilizando-se o método de manejo TCA, apresentados na Tabela 1 , resultou num aumento de $18,3 \%$ a mais de lâmina de água aplicada em relação ao método do TS. Já no sistema PC, a precipitação pluviométrica mais irrigação utilizando-se o método de manejo TCA, resultou num aumento de $17 \%$ a mais de água aplicada em relação ao método do TS. Portanto estes resultados foram similares aos obtidos por Cunha et al., (2013), encontraram uma lâmina de 29,7\% a mais para o TCA em relação ao manejo com o TS, em semeadura direta. Pavani et al., (2008), verificaram que a lâmina total estimada por TS foi 17,2 e $26,2 \%$ menor que a estimada pelo método do TCA, em PD e PC, respectivamente.

Os valores das lâminas de água aplicadas encontram-se dentro da faixa de $300 \mathrm{~mm}$ a 600 $\mathrm{mm}$, citada na literatura para a obtenção de incrementos da produtividade (SILVEIRA; STONE, 2004; PAVANI et al., 2008).

Tabela 1. Precipitações pluviométricas e lâmina de irrigação no ciclo do feijoeiro nos sistemas plantio direto e convencional.

\begin{tabular}{cccccc}
\hline \multirow{2}{*}{ Plantio } & $\begin{array}{c}\text { Precipitação } \\
(\mathrm{mm})\end{array}$ & \multicolumn{4}{c}{ Métodos de Irrigação (mm) } \\
\cline { 3 - 6 } & 248,9 & 0 & 110 & 187 & 192,6 \\
\hline PD & 248,9 & 0 & 120 & 190 & 195,7 \\
PC & & &
\end{tabular}

(TO) Testemunha; (TS) Tensiômetro; (PM) PenmanMonteith ; (TCA) Tanque Classe A.
Não foram observadas diferenças significativas quanto à eficiência no uso da água, o valor médio observado neste trabalho, 7,94 e 8,61 $\mathrm{kg} \mathrm{mm}^{-1}$ de água aplicado, para o sistema PD e PC. Sendo este semelhantes ao especificado por Cunha et al., 2013 o qual não verificaram diferenças significativas com valor médio de $8,86 \mathrm{~kg} \mathrm{~mm}^{-1}$ de água aplicado. Os resultados obtidos diferem daqueles encontrados por Pavani et al. (2008) em que o manejo de irrigação pelo tanque proporcionou maior eficiência de uso de água pela cultura.

No sistema PC, a maior média de produtividade foi observada no método TCA (3.971 kg ha-1), (Tabela 2) com uma lâmina total de 444,6 mm, com um consumo de 1.120 litros de água para produzir $1 \mathrm{~kg}$ de feijão. Este valor encontra-se abaixo do verificado por Silveira e Moreira (1990) no período de outonoinverno na região de cerrados, com uma produtividade de $2.325 \mathrm{~kg} \mathrm{ha}^{-1}$ e uma lâmina de $447 \mathrm{~mm}$, consumiu 2.000 litros de água para produzir $1 \mathrm{~kg}$ de feijão.

Não foram observadas diferenças significativas quanto à produtividade de grãos kg.ha ${ }^{-1}$, entre os sistemas PD e PC, mas foi significativo para os métodos de manejo de irrigação TCA, em relação TS, no sistema PC, com valor médio de (3.971 e 3.391 kg.ha ${ }^{-1}$ ) respectivamente, e não significativo para os métodos TCA, PM e TS no sistema PD. Pavani et al., (2008), para o PC verificaram diferença significativa entre os métodos TCA em relação 
ao TS, com valores de $(3.394,6$ e $1.865,6$ kg.ha-1) respectivamente, no $\mathrm{PD}$ não houve diferença na produtividade entre os manejos de irrigação.

Tabela 2 Componentes de produtividade da cultura do feijoeiro cultivar BRS Pontal.

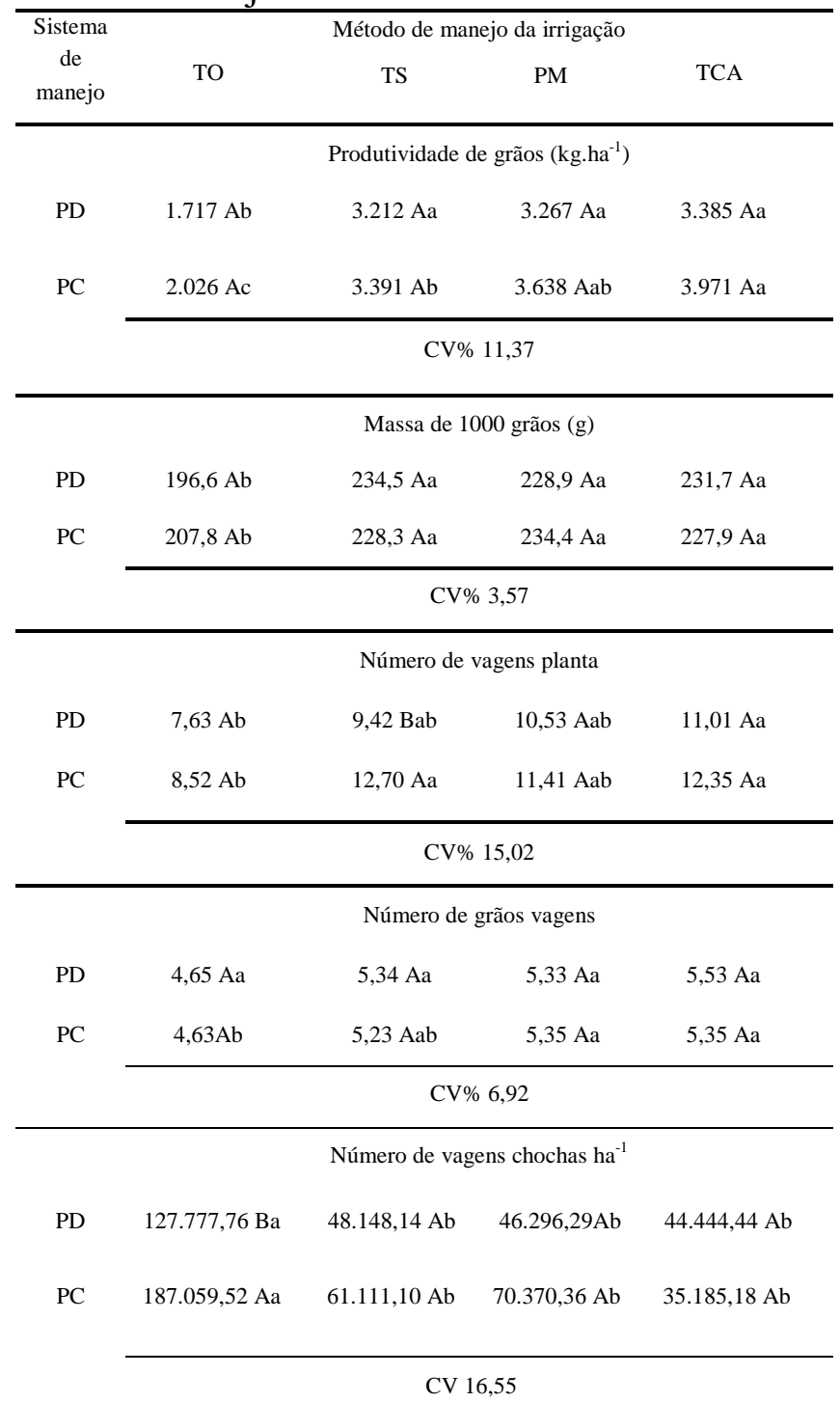

Médias seguidas de letras distintas, maiúsculas nas colunas e minúsculas nas linhas, diferem si, pelo teste de Tukey $(\mathrm{P}<0,05)$, (PD) Plantio direto; $(\mathrm{PC})$ plantio convencional; (TO) Testemunha; (TS) Tensiômetro; (PM) Penman-Monteith; (TCA) Tanque Classe A.

As médias de produtividade de grãos obtidas nas testemunhas resultaram em redução na produtividade, em relação ao TCA, de 49,3\% e 49,0\%, nos sistemas PD e PC, respectivamente, com diferença significativa. Guimarães et al (2011) obteve uma redução de 41,41\% na produtividade de grão, quando houve deficiência hídrica, durante dois anos de cultivo.

Quanto à massa média de 1000 grãos, não houve efeito significativo entre os sistemas PD e PC, e para as lâminas de irrigação estimadas pelos métodos de manejo de irrigação TCA, PM e TS, mas estes difere da TO. Obteve-se média de 231,7 e 230,2g para a condição irrigada para os sistemas PD e PC respectivamente. Cunha et al., 2013, em estudo semelhante não verificaram diferença significativa. Os resultados observados neste trabalho diferem dos obtidos por Pavani et al. (2008) que, de forma similar, avaliaram o desempenho do TCA e TS em PD e verificaram efeito dos regimes hídricos diferenciados sobre a massa de 1000 grãos do feijoeiro.

Quanto ao número de vagens por planta, entre os sistemas PD e PC houve diferença significativa, para o método do TS Tabela 2. Para o sistema PD a maior média é de $(11,01)$ observadas com o manejo pelo método do tanque Classe A, significativamente diferente da TO, más estes não difere dos métodos PM e TS. Para o PC, a maior média é de $(12,70)$, obtido pelo TS, significativamente diferente da TO não sendo diferente dos demais métodos. Resultado semelhante foi obtido por Cunha et al., 2013 com média de 12,77 vagens por planta, onde não verificou diferença significativa para os métodos de manejo TCA, PM e TS. 
Santana et al. (2008) também não observaram diferenças no número de vagens por planta mesmo com níveis de reposição de água no solo variando de 40 a $160 \%$ da lâmina necessária para elevá-lo à “capacidade de campo”. Tais resultados diferem dos observados por Pavani et al. (2008) que obtiveram maior número de vagens no feijoeiro manejado com tanque Classe A quando comparado com o manejo por tensiometria em condições de plantio direto, no inverno.

Não foram observadas diferenças significativas quanto ao número de grãos vagens, entre os sistemas PD e PC, mas foi significativo para os métodos de manejo de irrigação TCA, e PM em relação a TO, no sistema PC, com valor médio de (5,35; 5,35 grãos) respectivamente. Não houve o mesmo comportamento para o sistema PD, onde os métodos de manejo da irrigação TCA, PM e TS não difere da TO. Binotti et al. (2007) afirmaram que o número de grãos por vagem está mais relacionado com a cultivar utilizada, do que com as práticas culturais utilizadas na cultura do feijoeiro, como a irrigação, sofrendo pouca influência das mesmas, sendo que estes valores normalmente estão na ordem de 4 a 5 grãos por vagem.

A média de vagens chochas por ha, nos dois sistemas de manejo do solo, apresentou o menor valor para o método TCA, com (44.444) para o PD e (35.185) para o PC, sem diferença entre os métodos. Entre os sistemas PD e PC não houve diferença significativa.
Nos sistemas PD e PC, as testemunhas anteciparam o ciclo do feijoeiro em relação aos que foram irrigadas. O ciclo do feijoeiro foi de 85 dias para a TO em ambos os sistemas de plantio, enquanto que para os métodos de manejo TS, PM e TCA, nos plantios PD e PC os ciclos foram de 90, 92 e 92 dias respectivamente.

\section{CONCLUSÃO}

Os métodos de manejo da irrigação baseados no tanque classe $\mathrm{A}$ e na equação de Penman-Monteith apresentaram uma lâmina média de água aplicada maior que o método do tensiômetro.

A irrigação independente do método de manejo no sistema plantio direto e convencional foi significativo em relação a testemunha;

A relação entre a lâmina aplicada pelo método do tensiômetro e o tanque classe $\mathrm{A}$ foi de $82 \%$, demonstrando que foram adicionados $22 \%$ a mais de água ao utilizar o tanque classe A.

\section{REFERÊNCIAS BIBLIOGRÁFICAS}

ABRANTES, F. A.; SÁ, M. E.; SOUZA, L. C. D.; SILVA, M. P.; SIMIDU, H. M.; ANDREOTTI, M.; BUZETTI, S.; VALÉRIO 
FILHO, W. V.; ARRUDA, N. Uso do regulador de crescimento em cultivares de feijão de inverno. Pesquisa Agropecuária Tropical, Goiânia, v. 42, n. 21, p. 148-154, 2011.

ALLEN, R. G.; PEREIRA, L. S.; RAES, D.; SMITH, M. Crop evapotranspiration: guidelines for computing crop water requirements. Rome: FAO, 1998. (FAO Irrigation and Drainage Papers, 56).

ALVES JUNIOR, J.; SILVEIRA, P. M. da; STONE, L. F.; CUNHA, P. C. R. da. Retenção de água pelo dossel do feijoeiro irrigado por aspersão. Irriga, Botucatu, v.15, n.1, p.90-97, 2010.

BRAGA, M. B.; CALCARO, M.; MOURA, M. S. B.; SILVA, T. G. F. coeficientes do tanque classe "A" para estimativa da evapotranspiração de referencia na região do Vale do Submédio São Francisco, estado da Bahia. Revista de Agrometeorologia, v. 16, n. 1, p 49-57, 2008.

CONAB. Companhia Nacional de Abastecimento. Disponível: <http://www.conab. gov.br/OlalaCMS/uploads/arquivos/14_02_11_ 15_22_20_boletim_graos_fevereiro_2014.pdf>. Acesso em: 13 fev. 2014.

CUNHA, A. R., MARTINS, D. Classificação climática para os municípios de Botucatu e São Manuel, SP. Irriga, Botucatu, v. 14, n. 1, p. 111, 2009.

CUNHA, P. R da.; SILVEIRA, P. $\mathrm{M}$ da.; NASCIMENTO, J. L do.; ALVES JÚNIOR. J. Manejo da irrigação no feijoeiro cultivado em plantio direto. Revista Brasileira de Engenharia Agrícola e Ambiental, Campina Grande, v. 17, n. 7, p. 735-742, 2013.

DOORENBOS, J.; KASSAM, A. H. Efeito da água no rendimento das culturas. Tradução de H. R. Gheyi, A. A. de Souza, F. A. V. Damasco, J. F. de Medeiros.Campina Grande:
UFPB, 1994. 306 p. (Estudos FAO: Irrigação e drenagem, 33).

EMBRAPA. Centro Nacional. Pesquisa em solos. Sistema brasileiro de classificação de Solos. Brasília: Embrapa-SPI; Rio de janeiro: Embrapa solos, 2006. 306p.

GALBIATTI, J. A.; SILVA, F. G.; FRANCO, C. F.; CARAMELO, A. D. Desenvolvimento do feijoeiro sob o uso de biofertilizante e adubação mineral. Revista Engenharia Agrícola, Jaboticabal, v. 31, n. 1, p. 167-177, 2011.

GUIMARAES, C. M.; STONE, L. F.; DEL PELOSO, M. J.; OLIVEIRA, J. P de. Genótipos de feijoeiro comum sob deficiência hídrica. Revista Brasileira de Engenharia Agrícola e Ambiental, Campina Grande, v. 15, n. 7, p. 649-656, 2011.

GUIMARÃES, G. M.; STONE, L. F.; BRUNINI, O. Adaptação do feijoeiro comum (Phaseolus vulgaris L.) à seca. Revista Brasileira de Engenharia Agrícola e Ambiental, Campina Grande, v. 10, n. 1, p. 7075, 2006.

NÓBREGA, J. Q.; RAO, T. V. R.; BELTRÃO. N. E. de M.; FIDELES FILHO, J. Avaliação do efeito do estresse hídrico no rendimento do feijoeiro por sensoriamento remoto termal. Revista Brasileira de Agrometeorologia, Santa Maria, v. 12, n. 2, p. 299-305, 2004.

PAULA JUNIOR, T. J. de; VIEIRA, R. F.; TEIXEIRA, H.; COELHO, R. R.; CARNEIRO, J. E. de; ANDRADE, M. J. B. de; REZENDE, A. M. (Coords.). Informações técnicas para o cultivo do feijoeiro-comum na região central brasileira: 2007-2009. Belo Horizonte: EPAMIG, 2008. 180.p (EPAMIG. Documentos, 42).

PAVANI, L. C.; LOPES, A. S.; GALBEIRO, R. B. Manejo da irrigação na cultura do feijoeiro 
em sistemas plantio direto e convencional. Engenharia Agrícola, Jaboticabal, v. 28, n. 1, p. 12-21, 2008.

RAIJ, B. van.; ANDRADE, J .C.; CANTARELLA, H.;QUAGGIO, J. A. Análise química da fertilidade dos solos tropicais. Campinas: IAC, 2001, 285 p.

SANTANA, M. J.; CARAVALHO, J. A.; ANDRADE, M. J. B.; BRAGA, J. C.; GERVÁSIO, G. G. Coeficiente de cultura e análise do rendimento do feijoeiro sob regime de irrigação. Irriga, v.13, p.92-112, 2008.

SILVA. A. A. G.; BARRETO, A. N. Caracterização do solo e clima: técnicas para um manejo de irrigação otimizada. In: BARRETO, A. N.; SILVA, A. A. G.; BOLFE, E. L. (Ed.) Irrigação e drenagem na empresa agrícola: impacto ambiental versus sustentabilidade. Aracaju: Embrapa Tabuleiros Costeiros; Campina Grande: Embrapa Algodão, 2004, p. 13-45.

SILVEIRA, P. M. da; RAMOS, M. M.; OLIVEIRA, R. A. de. Manejo da irrigação do feijoeiro com o uso do irrigâmetro. Santo Antonio de Goiás: Embrapa Arroz e Feijão, 2009. 4 p. Embrapa Arroz e Feijão.
Circular técnica, 84).

SILVEIRA, P. M. da; STONE, L. F. Irrigação. Informe Agropecuário, Belo Horizonte, v. 25, n. 223, p. 74-82, 2004.

SILVEIRA, P. M.; MOREIRA, J. A. A. Respostas do feijoeiro a doses de fósforo e lâminas e água de irrigação. Revista Brasileira Ciência do Solo, Santo Antônio de Goiás, GO, v. 14. p. 63-67, 1990.

SNYDER, R. L. Equation for evaporation pan to evapotranspiration conversions. Journal of Irrigation and Drainage Engineering, New York, v. 118, n. 6, p. 977980, 1992.

STONE, L. F.; SILVEIRA, P. M. da; MOREIRA, J. A. A.; BRAZ, A. J. B. P. evapotranspiração do feijoeiro irrigado em plantio direto sobre diferentes palhadas de culturas de coberturas. Pesquisa agropecuária brasileira. Brasília, v. 4, n. 4, p. 577-582, 2006.

TAIZ, L.; ZEIGER, E. Fisiologia vegetal. 4. ed. Porto Alegre: Artmed, 2009. 820 p. 